\title{
ARTIGO
}

\section{Sistema hipermídia ajudando a construir a pesquisa escolar}

\section{The Hypermedia System "Helping to build the elementary-school research"}

Ana Maria Nogueira MACHADO ${ }^{1}$

Silvana Aparecida Borsetti Gregório VIDOTTI ${ }^{2}$

\section{RES U M O}

\begin{abstract}
Este trabalho surgiu da constatação das condições em que alunos de $1^{\text {a }}$ a $4^{\text {a }}$ séries do $1^{\circ} \mathrm{grau}$, hoje ensino fundamental, vinham à biblioteca para elaborar a chamada pesquisa escolar. O objetivo deste artigo é discutir o desenvolvimento do sistema hipermídia Ajudando a construir a pesquisa escolar, com enfoque na elaboração de referências, de acordo com a NBR 6023/2000 da Associação Brasileira de Normas Técnicas. O sistema foi construído no software Personal Brain $^{T M}$ que possui características estruturais em forma de rede. Estas possibilitam a criação de um ambiente hipermídia informacional, pessoal ou coletivo, numa relação natural entre as informações armazenadas em documentos e os temas abordados pelos usuários. Acredita-se que o sistema aqui discutido, pode ser utilizado como um instrumento motivador da pesquisa escolar.
\end{abstract}

Palavras-chave: pesquisa escolar, sistema hipermídia educacional, NBR 6023 - Referências, motivação, Personal Brain TM.

\section{A B S T R A C T}

This work was motivated by the intent to change the conditions in which elementary school students, from 1 rst to 4rth grade use to come to the library in order to do

\footnotetext{
${ }^{1}$ Doutora e Bibliotecária em Educação, Universidade Estadual Paulista - UNESP, Campus de Marília.

2 Doutora em Educação, Docente do Departamento de Ciência da Informação, Universidade Estadual Paulista - UNESP, Campus de Marília. Grupo de Pesquisa - N ovas Tecnologias em Informação.

Recebido e aceito para publicação em 8/7/2003.
} 
school-research. This article's objective is to discuss the development of the Hypermedia System Helping to build the elementary-school research, focusing on reference elaboration, in accordance with the NBR 6023/2000 of the Brazilian Association of Technical Norms. The system was built in the software Personal Brain TM that has structural characteristics in net form. The latter make possible to create an informational hypermedia environment, personal or shared, in a natural relationship between the document-stored information and the themes approached by the users. The discussed hypermedia system seems apt to become a motivating tool for the school research.

Key Words: school research, educational hypermedia system N B R 6023 - references, Personal Brain TM.

\section{N T R O D U Ç Ã O}

Nossa preocupação com o desenvolvimento da pesquisa científica vem desde a graduação e foi corroborada com avaliações de trabalhos apresentados aos Cursos de PósGraduação. Alguns trabalhos científicos neste sentido foram publicados, como os de Bueno \& Vidotti $(1999,2000)$ sobre ferramentas de busca na Internet, os de Vidotti $(1997,2001)$ sobre sistemas hipermídia na Educação e no processo de ensino-aprendizagem, e a dissertação de mestrado de Machado (1989) intitulada Pesquisa Escolar: uma questão para resolver, sendo que este último deu-nos a oportunidade de constatar em que condições o aluno do $1^{\circ}$ grau, hoje Ensino Fundamental, chegava à Biblioteca para elaborar a chamada pesquisa escolar.

Alguns resultados obtidos na investigação de Machado (1989) podem constituir-se em ponto de partida para a elaboração dessa proposta de construção de um sistema hipermídia Ajudando a construir a pesquisa escolar, a saber:

a) constatamos a perplexidade do escolar diante do material bibliográfico, (que se restringe a um único livro), como característica inicial do estudante que deve realizar a pesquisa escolar. Ressalta-se que a avaliação do professor solicitava que, após a pesquisa bibliográfica, o estudante produzisse um texto que sintetizasse a busca;

b) os sujeitos daquele estudo chegavam à Biblioteca tendo em mãos temas de uma amplitude tal, que escapavam às suas reais possibilidades de assimilação. Os temas na sua ampla maioria (80\%), eram impostos pelo docente que não levava em consideração requisitos primordiais para o êxito da pesquisa, ou seja, satisfação das necessidades e interesses individuais;

c) em relação a questão que averiguava as condições em que ocorria a pesquisa escolar, ou seja, a elaboração da mesma, aliada à obtenção de nota e até mesmo à punição, foi responsável por $55 \%$ das respostas;

d) a ausência de um plano orientador ou de um roteiro, indicou que, segundo a ótica do professor, os alunos deveriam ter iniciativa própria, isto é, entendida por parte dos docentes como algo que se dá por geração espontânea e não como algo derivado de uma ação pedagógica cuidadosamente preparada;

e) no que diz respeito à indicação de material bibliográfico para consulta, a enciclopédia e o livro didático apareceram, em $20 \%$ dos casos, como os únicos textos recomendados;

f) a falta de conhecimento do aluno, quanto ao uso da Biblioteca, como ficou evidenciado, dificultava substancialmente o desenvolvimento de sua pesquisa, como também colaborava para acentuar o distanciamento dele do contato com o livro. Quando esta oportunidade se dava o estudante não sabia o que fazer para obter os dados de que necessitava; 
g) as vias de acesso às informação eram totalmente desconhecidas dos sujeitos, visto que os mesmos se dirigiam diretamente ao responsável pelo balcão de atendimento da Biblioteca;

h) observamos que de posse do material bibliográfico, previamente assinalado pelo atendente da biblioteca, na página que indicava o assunto da pesquisa, $95 \%$ dos sujeitos copiavam o texto no todo ou em parte.

Ainda entre os resultados desse trabalho, para se tornar conhecida a forma como o escolar expunha elementos da(s) obra(s), utilizada(s) na elaboração do trabalho escolar e também para se identificar outros dados relevantes, Machado (1989) julgou oportuno solicitar uma cópia do texto produzido quando estivesse concluído: os resultados foram os seguintes:

a) do total de textos coletados, apenas $19,5 \%$ vieram acompanhados de elementos que indicavam a obra utilizada. Os escolares, apesar de conhecerem o valor atribuído à indicação bibliográfica, não faziam uso dela, talvez por acreditarem em sua irrelevância para o professor, no momento da avaliação;

b) quando da identificação dos agentes que influenciaram na aprendizagem de como fazer pesquisa, esperávamos que os profissionais que trabalhavam nos locais, tidos como privilegiados para desenvolvimento do processo de elaboração da pesquisa (professor/ bibliotecário) recebessem o maior número de preferências. No entanto, o resultado não confirmou nossas expectativas, visto que $62,5 \%$ dos respondentes disseram ter aprendido por iniciativa própria. Os professores e os bibliotecários receberam respectivamente $20 \%$ e $0 \%$ das preferências;

c) a ausência total de referência ao funcionário da Biblioteca apenas veio a confirmar as situações que levantamos através da literatura sobre o assunto, aliadas àquelas que descrevem a imagem do bibliotecário como profissional que tem servido, com grande freqüência, apenas para processar tecnicamente os materiais bibliográficos.

Estudos atuais apresentados na literatura científica somados ao de Machado (1989) dizem que aos escolares do ensino fundamental, falta uma orientação de pesquisa adequada ao seu desenvolvimento cognitivo e seus interesses pessoais, a fim de que haja melhor aproveitamento do tempo e da oportunidade de conhecimento (auto-conhecimento) que se lhes estão sendo dados.

Os professores, em geral, não ensinam metodologia de pesquisa aos alunos, porquanto eles próprios não a dominam, por não terem recebido, ao longo de sua formação, orientação apropriada quanto à organização da informação e formas de auxílio à assimilação pessoal das mesmas com vistas à produção de um texto.

Assim, julgamos oportuno, ao invés de abandonar a prática da pesquisa escolar, em função dos resultados obtidos, elaborar um trabalho a fim de viabilizá-la. Desenvolvemos, então, o sistema hipermídia: Ajudando a construir a pesquisa escolar que contempla itens de como fazer e organizar referências, as mais comumente utilizadas por pesquisadores iniciantes, de acordo com a Associação Brasileira de Normas Técnicas (ABNT), como parte da pesquisa bibliográfica.

A história da hipermídia é marcada por alguns autores destacando-se os trabalhos de Bush (1945), idealizou o conceito de hipertexto; de Douglas Engelbart que, em 1962, fez uma demonstração de um sistema de aplicação da idéia de Bush ao computador; e o de Ted Nelson, cunhando o termo hipertexto em 1965, em suas aplicações na área de literatura.

Baseado na estrutura convencional de uma biblioteca e motivado a desenvolver suas idéias pela necessidade de suportar formas naturais de indexação e recuperação de informações, o matemático e físico Bush, em 1945, em seu artigo intitulado As we may think, idealizou 
o sistema precursor dos sistemas hipertextuais, o Sistema Memex (Memory Extender): "[...] um dispositivo no qual um indivíduo armazenaria todos os seus livros, registros e comunicações, e seria mecanizado de tal forma que pudesse ser consultado com alta flexibilidade e velocidade [...] um suplemento da própria memória do indivíduo" (BUSH, 1945).

O sistema de recuperação proposto por Bush (1945), quando o estudo do behavorismo encontrava-se em voga, era o de associação de idéias, objetos ou itens, supostamente semelhante ao que ocorre no cérebro humano:

[...] a mente humana [...] opera por associação. Com um item enfocado, ela pula instantaneamente, para o próximo item sugerido pela associação de pensamentos, de acordo com alguma teia intrincada de caminhos formada pelas células do cérebro. A mente tem naturalmente outras características: trilhas que não são seguidas freqüentemente podem ser apagadas, os itens não são totalmente permanentes, a memória é transitória. Ainda assim, a velocidade de ação, a complexidade das trilhas, os detalhes das imagens mentais são mais espantosos que qualquer coisa na natureza [...] O homem não pode esperar que esse processo mental seja completamente reproduzido artificialmente, mas deve ser capaz de aprender com isto. Ninguém pode esperar igualar a velocidade e flexibilidade com a qual a mente humana segue um caminho associativo, mas talvez seja possível vencer a mente no que diz respeito à permanência e a clareza dos itens recuperados do armazenamento.
O Sistema Memex proposto por Bush (1945) foi projetado como um dispositivo no qual o usuário guardaria todos os seus livros, revistas, jornais, fotos e correspondências podendo consultá-los de forma rápida e flexível, como se fosse uma extensão de sua memória. O armazenamento das informações seria feito em microfichas, microfilmes ou fitas e o acesso a essas informações seria mecânico e através de índices. $\mathrm{O}$ acesso às informações seria feito através de uma tela de televisão munida de altofalantes. Além dos acessos clássicos por indexação, um comando simples permitiria ao usuário criar ligações independentes de qualquer classificação hierárquica entre uma dada informação e outra. Uma vez estabelecida a conexão, cada vez que determinado item fosse visualizado, todos os outros que tivessem sido ligados a ele poderiam ser instantaneamente recuperados, através de um simples toque em um botão (VIDOTTI, 2001).

O sistema Memex foi projetado em detalhes, mas as tecnologias disponíveis na época não permitiram a sua implementação. As idéias de Bush, entretanto, influenciaram, 20 anos depois, outros pioneiros de hipertexto, dando início à primeira geração de sistemas hipertexto, com o surgimento dos computadores digitais.

As tecnologias de informática, somente nos anos de 1990, possibilitaram acelerado desenvolvimento de sistemas multimídia/ hipermídia e de realidade virtual. Hoje, os recursos de multimídia estão disponíveis no mercado brasileiro, enquanto que a tecnologia de realidade virtual enfrenta, ainda, dificuldades tanto de ordem técnica quanto de ordem econômica.

Tornou-se consenso utilizar o termo multimídia para designar, genericamente, o processo de transmitir informação utilizando os recursos integrados de textos, imagens, diagramas, animações, sons e vídeo, sob a monitoração do computador. Conforme Vidotti e 
Santos (1995), "hipermídia ou multimídia interativa não é apenas a soma de diversas mídias, mas a interação dessas mídias, via computador, de maneira a envolver o usuário no processo de exploração de um sistema informacional".

Em seu livro As tecnologias da inteligência: o futuro do pensamento na era da Informática, o filósofo Lévy (1993, p.25) elabora uma noção mais ampla de hipertexto para referirse aos mundos de significações veiculados pela comunicação, e que incorporam as tecnologias de informática, podendo envolver conjuntamente texto, imagens e sons, modificando radicalmente as formas de recurso à memória e integrando múltiplos canais perceptivos: "O hipertexto é talvez uma metáfora válida para todas as esferas da realidade em que significações estejam em jogo".

O fundamental no processo referente ao hipertexto é a possibilidade de interação do homem com a máquina, ressaltando que, por trás desta está um número variável de profissionais que se somam a fim de permitir que isso ocorra. A partir dessa interatividade, qualquer ramificação de determinado assunto pode ser explorada pelo usuário do equipamento e dos aplicativos, explica Gonçalves (1992, p.3).

A tecnologia coloca hoje à nossa disposição métodos e materiais que permitem um processo de aprendizagem individual e personalizado o que pode tornar a pessoa mais autônoma e mais independente, com maior iniciativa para tomar decisões por conta própria. Para Moran (1994), a tecnologia aproxima pessoas e grupos, democratizando a informação e possibilitando novas formas de comunicação educativa.

Pautando-nos no surgimento de novas tecnologias, nos atuais suportes de informação, nos ideais do sistema Memex de Bush (1945), na associação de idéias de Hume (1962), e na teoria de assimilação cognitiva de Piaget (1973), como referencial teórico do processo de ensino- -aprendizagem, nos propomos a elaborar um ambiente hipermídia para o ensino de referência, parte da pesquisa bibliográfica.

Vale salientar que, neste texto, não fazemos a distinção dos termos Hipertexto e Hipermídia e os definimos como um sistema que possibilita o armazenamento, interligação, recuperação e apresentação de informações por meio da interação de mídias (som, imagem, e texto), e que contempla a rede informacional com os princípios abstratos (metamorfose, heterogeneidade, multiplicidade e encaixe das escalas, exterioridade, topologia e mobilidade dos centros) apresentados por Lévy (1993).

Pretendemos através deste trabalho teórico-prático, contribuir para a estruturação da pesquisa bibliográfica - escolar ou não - imprimindo a ela um caráter emancipatório a fim de que os pesquisadores se conscientizem da necessidade de se tornarem sujeitos ativos do processo de construção do conhecimento.

Com a popularização da rede de comunicação Internet, em especial com o desenvolvimento da estrutura hipertextual da World Wide Web, passamos a dispor de novas ferramentas para a construção do conhecimento no processo de ensino-aprendizagem, e a entender que essa tecnologia possibilita a comunicação e o intercâmbio entre diferentes pessoas de diferentes locais e culturas, bem como a troca de experiência e ainda um vasto universo informacional para a pesquisa individual e/ou em grupo.

A navegação e seleção de informações/ documentos na imensa rede hipertextual da World Wide Web podem ser administradas por um sistema organizador de documentos que permite as interligações de endereços e arquivos, formando uma rede documental de fontes primárias e secundárias estruturada pelo usuário no momento da seleção. A esta estrutura dinâmica de interligação dos documentos podem-se interligar outros documentos que, por sua vez, se encontram armazenados em diferentes 
suportes informacionais, criando assim um ambiente hipermídia personalizado.

Para a elaboração do ambiente/sistema hipermídia educacional - Ajudando a construir a pesquisa escolar - foi selecionado o software PersonalBrain ${ }^{T M}$ - versão 1.74 , que possui características estruturais em forma de rede as quais possibilitam a criação de um ambiente hipermídia pessoal ou coletivo numa relação natural entre as informações armazenadas em documentos e assuntos/temas abordados (VIDOTTI, 2001).

Esse ambiente possui inicialmente informações sobre: como utilizar o ambiente hipermídia; Internet e as ferramentas de busca de informações; etapas de produção de textos e, como fazer a referência. Possui ainda nós informacionais que podem ser utilizados para a inclusão do levantamento bibliográfico, dos documentos selecionados, bem como dos textos produzidos.

O software PersonalBrain ${ }^{T M}$, em sua estrutura funcional, utiliza um formato de dados chamado thoughts (pensamentos). Estes podem ser interligados por critérios escolhidos pelo usuário e podem conter qualquer tipo de informação, inclusive documentos, planilhas eletrônicas, imagens, atalhos e páginas de uma rede de computadores interna (Intranet) ou mundial (Internet). Ao permitir vínculos e relações entre pensamentos, o PersonalBrain ${ }^{T M}$ se expande para se tornar uma interface visual que reflete as relações de vizinhança de pensamentos em torno do pensamento ativo (VIDOTTI, 2001).

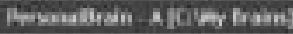
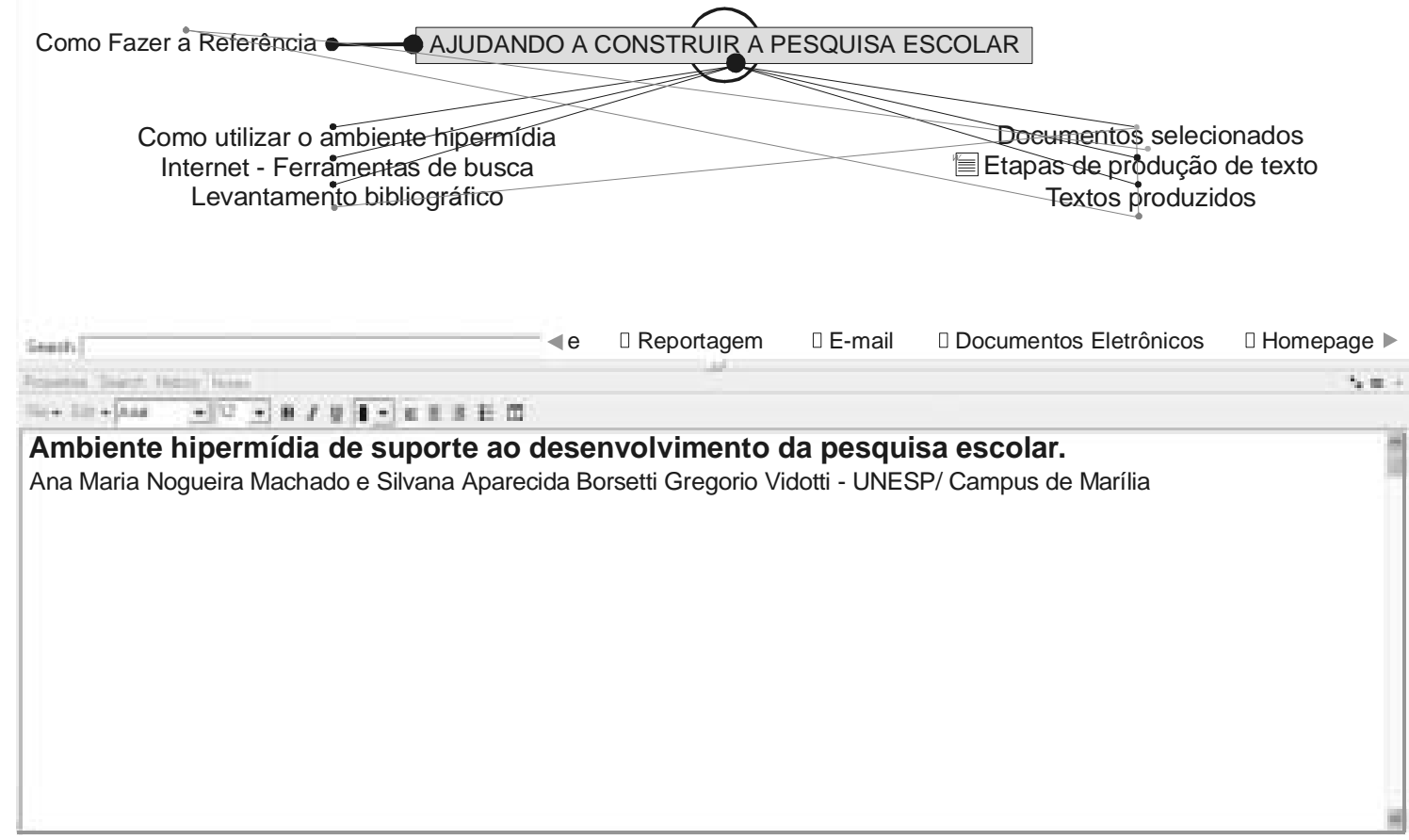

Figura 1. Sistema hipermídia - Nó informacional ajudando a construir a pesquisa escolar. 
A forma de exibição das interligações dos pensamentos se faz por meio de uma rede informacional que se inicia com um único pensamento, e ao qual passam a ser vinculados visualmente outros pensamentos. Estes novos pensamentos têm os seus próprios vínculos.

A estrutura do software permite unir pensamentos, de forma manual ou automática, além de possibilitar a desativação de alguns outros, em uma forma de esquecimento. A desativação de um pensamento pode se dar de forma dinâmica, com a reestruturação dos demais pensamentos interligados a estes.

Para um melhor entendimento do ambiente hipermída Ajudando a construir a pesquisa escolar, apresentamos a seguir a tela-"plex" do software PersonalBrain ${ }^{T M}$.

No centro do "plex", encontra-se o pensamento "thought" ativo - nó informacional "Ajudando a Construir a Pesquisa Escolar". $\mathrm{Na}$ parte inferior do nó ativo, estão relacionados os nós informacionais denominados "child thoughts": Como utilizar o ambiente hipermídia; Internet - Ferramentas de busca; Levantamento bibliográfico; Documentos selecionados; Etapas de produção de texto, e Textos produzidos. No lado esquerdo encontra-se o "jump thought": Como fazer a Referência-nó de destaque no ambiente.

Essa tela inicial apresenta os itens abordados nesse ambiente hipermídia que foram selecionados com o objetivo de orientar o usuário no desenvolvimento de sua pesquisa escolar. Os links em vermelho exibem a relação direta dos itens com o nó principal/ativo. Os links amarelos apresentam as interligações embutidas entre os itens principais.

Como o enfoque principal deste trabalho trata da elaboração de referências em, uma das etapas da pesquisa bibliográfica, construímos o nó informacional Como fazer a Referência, baseando-nos na NBR/6023, Informação e documentação - Referências - Elaboração, da Associação Brasileira de Normas Técnicas publicada em agosto de 2000.

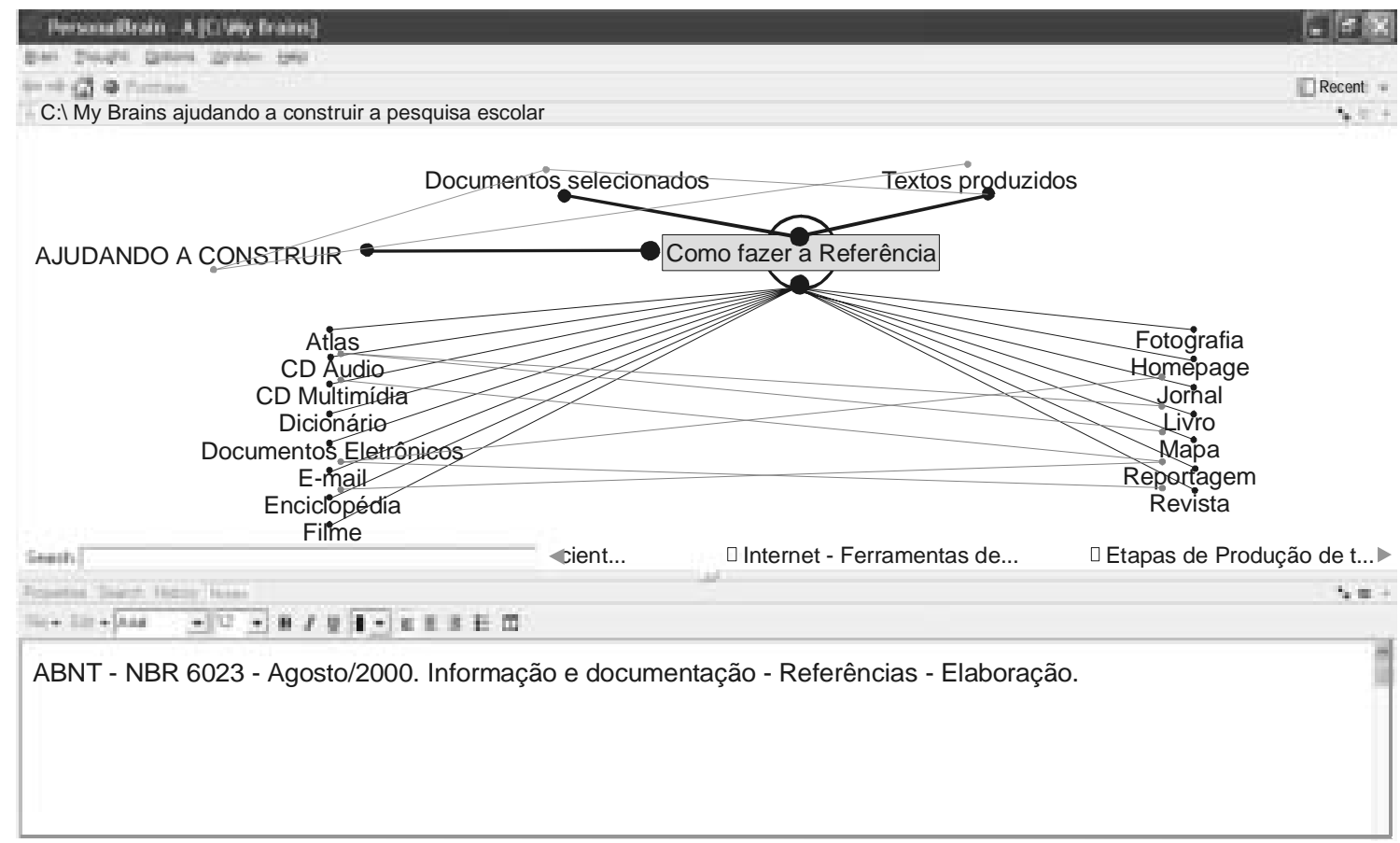

Figura 2. Nó informacional Como fazer a Referência. 
Os links, em vermelho, relacionados abaixo do nó Como fazer a Referência, mostram alguns tipos de materiais e de suportes em ordem alfabética e não em ordem de prioridade por considerarmos que esta depende de cada situação e de cada usuário. Os links em amarelo assinalam as possíveis ligações entre os diversos itens informacionais.

Os nós Documentos selecionados e Textos produzidos, apresentados na parte superior da Figura 2, tratam de situações nas quais ocorrem a necessidade de se elaborar as referências dos documentos selecionados e/ou utilizados.

Para ilustrar o modo como trabalhamos as referências, apresentamos a Figura 3 que contém um exemplo de referência de revista no todo, com a imagem da capa de um de seus fascículos, a referência de acordo com a NBR $6023 / 2000$, e a descrição dos seus elementos essenciais.

Como podemos perceber nas figuras apresentadas, o software PersonalBrain ${ }^{T M}$ permite ao usuário a organização das informações (documentos, arquivos, páginas da Web, etc.), em categorias hierárquicas ou em redes, de uma maneira compatível com a sua estrutura cognitiva. Cabe ao usuário tomar decisões, fazer escolhas sobre os critérios pelos quais os pensamentos serão relacionados (VIDOTTI, 2001).

\section{O N C L U S Ã O}

A utilização de um ambiente hipermídia dessa natureza favorece ao usuário-aluno uma
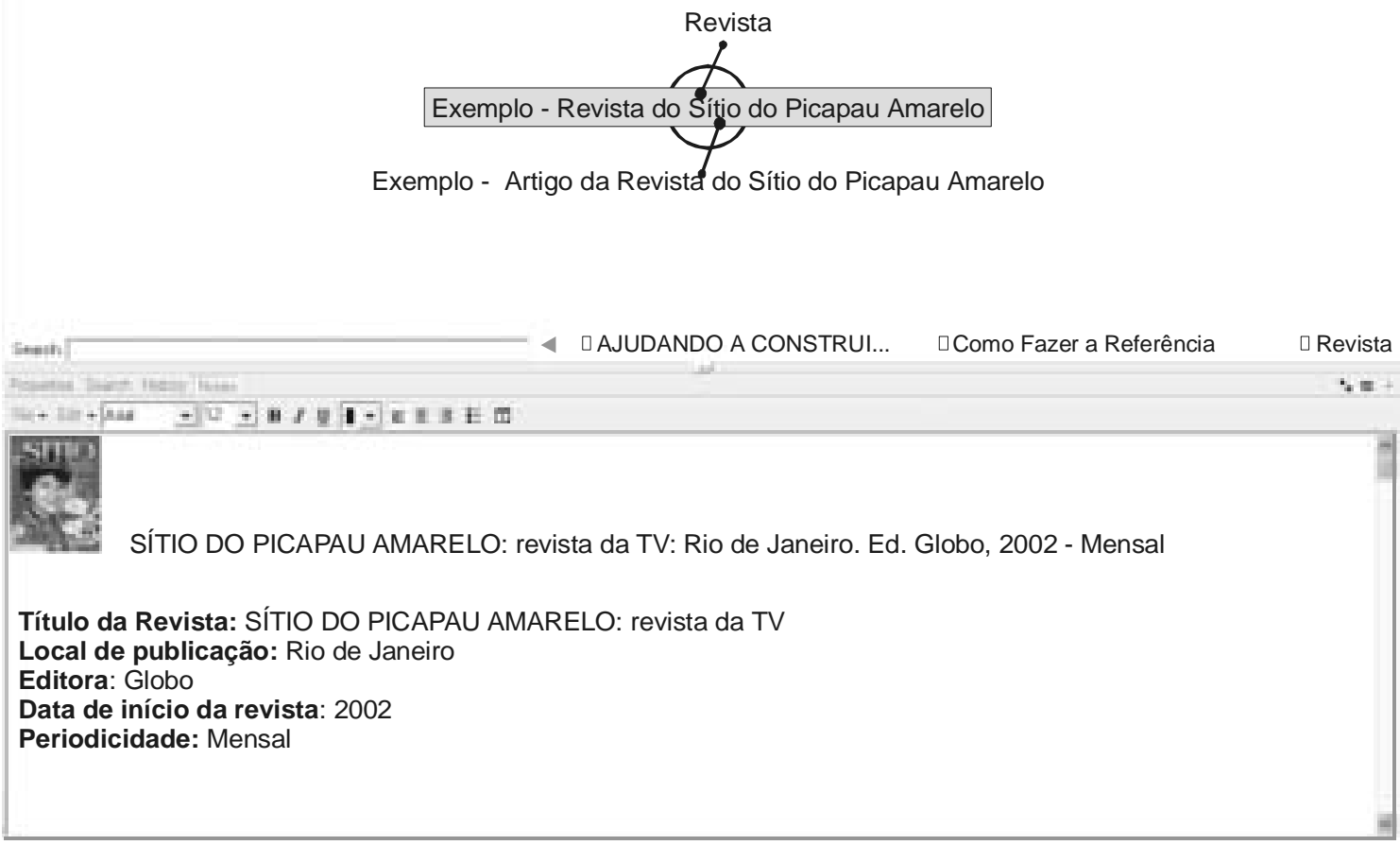

Figura 3. Nó informacional Exemplo - Revista do Sítio do Picapau Amarelo. 
melhor interação das suas atividades de pesquisa por meio da inclusão e interligação de documen-tos/informações em um processo de assimilação cognitiva.

\section{RE FERÊ N C IAS}

ASSOCIAÇÃO BRASILEIRA DE NORMAS TÉCNICAS. NBR/6023: informação e documentação: referências: elaboração. Rio de Janeiro, 2000.

BUENO, M. C.; VIDOTTI, S. A. B. G. Uso estratégico das ferramentas de busca na Internet. In: SIMPÓSIO INTERNACIONAL "PROF. DR. PAULO TARCÍSIO MAYRINK, 3., 1999, Marília. Anais... Marília: Faculdade de Filosofia e Ciências, 1999. p.39-49.

BUENO, M. C.; VIDOTTI, S. A. B. G. Ferramentas de busca na Internet: para quê, por quê e como utilizá-las? In: SEMINÁRIO NACIONAL DE BIBLIOTE-CAS UNIVERSITÁRIAS, 12, 2000, Florianópolis: UFSC, 2000.

BUSH, V. As we may think. The Atlantic Monthly. Jul. 1945. Versão eletrônica preparada por Denys Duchier, abril, 1994. Disponível em <http:// www.isg.sfu.ca/ duchier/misc/vbush>. Acesso em: 18 jul.1999.

GONÇALVES, A.T. Multimídia. v.3, n. 7, p.3-6, 1992.

HUME, D. Investigação acerca do entendimento humano. São Paulo: Nacional, 1962.

LÉVY, P. As tecnologias da inteligência: o futuro do pensamento na era da informática. Rio de Janeiro: Ed. 34, 1993. 203 p.
Acreditamos que o sistema hipermídia Ajudando a construir a pesquisa escolarpode ser utilizado pelos educadores como um elemen-to motivador no desenvolvimento da pesquisa escolar.

MACHADO, AM. N. Pesquisa escolar: uma questão para resolver. 1989. Dissertação (Mestrado em Biblioteconomia) - Faculdade de Bilbioteconomia - Pontifícia Universidade Católica, Campinas, 1989.

MORAN, J.M. Interferências dos meios de comunicação no nosso conhecimento. Revista Intercom: Revista Brasileira de Comunicação, São Paulo, v.17, n.2, 1994.

PIAGET, J. Biologia e conhecimento: ensaio sobre as relações entre as regulações orgânicas e os processos cognoscitivos. Petrópolis: Vozes, 1973.

VIDOTTI, S. A.B.G. Hipermídia na Educação. Marília, 1997. (Projeto Trienal de Pesquisa).

VIDOTTI, S.A.B.G. O ambiente hipermídia no processo de ensino-aprendizagem. Marília, 2001. Tese (Doutorado em Educação) - Faculdade de Filosofia e Ciências, Universidade Estadual Paulista.

VIDOTTI, S.A.B.G.; SANTOS, P.L.V.A.C. Hypermedia: metodology for storing and retrieving information. In: CONGRESO INTERNACIONAL DE INFORMACIÓN - INFO'95. Havana - Cuba, 1995. Anais... (Disquete). 
